\title{
DAKWAH KULTURAL DAN ISLAMISASI DI TERNATE
}

\author{
Sariyah Ipaenin \\ UIN Sunan Kalijaga Yogyakarta \\ ipaeninsariyah@gmail.com
}

\section{Abstract}

This article presents a study of the beginning of the cultural propagation movement amid Ternate society which still adheres to animist beliefs and dynamism. The spread of da'wah in Ternate cannot be separated from the Islamization process carried out by Arabs and Persians who trade and establish marriage ties with local communities. These immigrant community groups preach through cultural approaches by utilizing culture as a means, media, and targets. Cultural propaganda has the object of the majority of people who do not know Islam well. If they are familiar with Islam, the common goal is enthusiasm for culture and previous myths that still adhere to strong beliefs. The role and effectiveness of cultural dakwah are needed for the success of the Islamic mission in Indonesia, especially for the people of Ternate.

\section{Abstrak}

Artikel ini berkenaan dengan studi awal gerakan dakwah kultural pada masyarakat Ternate, yang masih menganut aliran kepercayaan anemisme dan dinamisme. Penyebaran dakwah juga tidak terlepas dari proses Islamisasi dari orang Arab dan Persia yang berdagang dan melakukan ikatan perkawinan pada masyarakat setempat. Di sisi lain dakwah melalui pendekatan kultural dengan memanfaatkan budaya sebagai sarana, media dan sasarannya. Dakwah kultural memiliki objek yang mayoritas masyarakatnya belum mengenal Islam dengan baik, dan apabila sudah mengenal islam dengan baik biasanya objek 
tersebut sangat fanatik dengan budaya dan mitos-mitos terdahulu yang masih menganut kepercayaan yang sudahsangat kental. Maka disinilah peran dan efektivitas dakwah kultural sangat dibutuhkan demi keberhasilan dakwah Islam di Indonesia. Terlebih khusus pada masyarakat Ternate.

Kata kunci: dakwah kultural, islamisasi, Ternate

DOI: 10.24239/al-mishbah.Vol14.Iss1.110

\section{A. Pendahuluan}

Agama Islam disinyalir telah sampai ke Nusantara sejak abad pertama Hijriah atau sejak era Nabi Muhammad saw. Terdapat beberapa pendapat yang menyebutkan bahwa awal penyebaran agama Islam hingga ke Nusantara terjadi pada abad ke-8 H./14 M. Akan tetapi, belum ada pengislaman yang masif terjadi pada kurun waktu tersebut. Baru pada abad berikutnya, konversi masyarakat ke dalam agama Islam terhadi secara besar-besaran. Sejarawan berpadangan bahwa peralihan keyakinan ini disebabkan oleh kehilangan pengaruh dan kekuatan politik yang ditandai dengan kejatuhan sejumlah kerajaan loka, seperti Kerajan Aceh Darussalam, Malaka, Demak, Cirebon, serta Tertane. Pesatnya pengaruh Islam di abad ke-15 juga tidak lepas dari faktor kekuatan dan pengaruh kerajaan Hindu dan Budha di Nusantara yang mengalami pelemahan. ${ }^{1}$

Pembacaan terhadap literatur-literatur sejarah menunjukkan bahwa Arab, Persia, dan Gujarat, merupakan tiga wilayah yang menjadi pintu masuknya Islam di Indonesia. Proses islamisasi pada umumnya terjadi melalui proses pedagangan, penikahan, dan hubungan sosial. Karakter islamisasi yang tidak memberangus kebudayaan lokal telah memberikan keunikan tersendiri dalam

1 Wahyu Ilaihi dan Harjani Hefni, Pengantar Sejarah Gerakan Dakwah (Jakarta: Kencana, 2007), 171. 
keberislaman masyarakat di Indonesia hingga membentuk tradisitradisi khusus. ${ }^{2}$

Ketika Islam datang, penduduk di Indonesia telah menganut animisme, dinamisme, serta ajaran Hindu dan Budha. Komunikasi interaktif di antara ajaran Islam dengan keyakinan-keyakinan tersebut tidak dapt dihindarkan. Dalam konteks ini tercipta komunikasi antar budaya, yaitu antara kebudayaan Islam dengan kebudayaankebudayan lokal, serta agama Hindu dan Budha. ${ }^{3}$

Sejarah penyebaran Islam di Maluku Utara diduga berasal dari Malaka, Kalimantan, dan Jawa. Sejumlah wilayah, seperti Banjar dan Giri atau Gresik dianggap memiliki pengaruh signifikan dalam sosialisasi Islam di Ternate dan Tidore. Hal ini terjadi sebelum era arus balik, yakni penyebaran Islam dari Ternate ke Buton dan daerah-daerah lainnya di Sulawesi Selatan.

Pola sosialisasi Islam di Ternate serupa dengan fenomena penyebaran Islam di daerah-daerah lainnya di Indonesia Bagian Timur, semisal Tidore, Jailolo, dan Mataram. Para elit dari kerajaankerajaan tersebut mempelajari agama Islam dari pusat-pusat pengajaran Islam di Nusantara, seperti Gresik, kemudian kembali dan mengislamkan masyarakat di kerajaan asalnya. ${ }^{4}$

Secara kelompok, masyarakat Ternate telah mengenal unsurunsur kebudayaan Islam melalui para pedagang yang juga kerap berperan sebagai mubalig. Pada taraf awal, tarik-menarik antara dua kebudayaan, yakni antara kebudayaan baru dan kebudayaan lokal, baik secara langsung maupun tidak langsung, merupakan fenomena yang lazim. Dalam perkembangannya, kebudayaan Ternate

2 Ibid., 172.

${ }^{3}$ Syamsuriah, "Tradisi Budaya dan Tradisi Agama dalam Kehidupan Sosial," Al-Mishbah: Jurnal Ilmu Dakwah dan Komunikasi 9, no. 1 (Juni 2013): 63-76.

${ }^{4}$ Hasan Muarif Ambary, Menemukan Peradaban Jejak Arkeologis dan Historis Islam Indonesia (Jakarta: Logos Wacana Ilmu, 1998), 153. 
mengalami dinamika yang dimulai dari zaman kolano (raja), era Islam, kolonialisme, hingga zaman modern. Pada masyarakat Ternate ditemukan unsur-unsur kebudayaan yang berasal dari Asia Tenggara dan Timur Tengah (Cina, Jepang, dan Arab) serta kebudayaan Barat (Portugis, Spanyol, dan Belanda). Artikel ini mengungkap pengaruh unsur keislaman di dalam kebudayaan Ternate sebagai bentuk dari hasil pendekatan dakwah kultural yang dilakukan oleh para juru dakwah di Ternate.

\section{B. Awal Penyebaran Islam di Ternate}

Mayoritas masyarakat Ternate beragama Islam. Realitas ini tidak lepas dari sejarah masa silam, di mana Ternate merupakan kerajaan pertama di Indonesia yang terislamkan. Hasil alam Ternate, yaitu pala dan cengkeh, telah menarik minat para pedaganga Arab Muslim untuk datang lebih awal ke wilayah ini. Kerajaan Ternate, pada mulanya, bukan kesultanan yang menganut ajaran agama Islam. Belum ditemukan sumber yang menyebutkan kepercayaan asli kerajaan dan masyarakat Ternate sebelum kedatangan Islam, sehingga dapat diasumsikan bahwa masyarakat setempat merupakan penganut animisme atau kepercayaan pada kekuatan-kekuatan gaib di sekitar gunung berapi Gamalama. Hubungan Islam dengan kerajaan Ternate, yang pada awalnya mewakili kepentingan dagang atau ekonomi, seperti yang disebutkan oleh Azyumardi Azra, berkembang menjadi hubungan religio-politik dan intelektual keagamaan seiring dengan faktor-faktor utama dalam penetrasi Islam di berbagai wilayah di Nusantara. ${ }^{5}$

Para penulis sejarah Maluku, baik asing maupun lokal, lazimnya merujuk sumber-sumber Portugis dalam menetapkan tahun awal tarikh kedatangan Islam di Ternate berdasarkan pelantikan Sultan Zainal Abidin dari Ternate, yakni 1486. Ketika dilantik, Raja Ternate menggunakan gelar Sultan yang islami serta melepaskan title

\footnotetext{
${ }^{5}$ Azyumardi Azra, Jaringan Ulama (Bandung: Mizan, 1995), x.
} 
tradisional, Kolano, yang digunakan oleh raja-raja sebelumnya sejak berabad-abad silam. ${ }^{6}$

Penanggalan lebih awal terkait islamisasi Ternate diajukan oleh Ajho. Menurutnya, Islam masuk di Kepulauan Ternate sejak abad XIV/XV, tepatnya pada masa kekuasaan Raja Gapi Baguna (14651486). Sebelum menarik minat Raja Gapi, Islam lebih dulu menyebar di masyarakat lokal berkat dakwah yang dilakukan oleh pedagangpedagang Muslim yang datang dari Jawa, di antaranya adalah Datuk Maulana Husin. Penyebaran Islam semakin mendapatkan kemudahan setelah dianut dan dijadikan ajaran resmi Kerajaan Ternate. Setelah memeluk Islam, Raja Gapi Baguna mengganti namanya menjadi Sultan Zainal Abidin. ${ }^{7}$

Tokoh kunci penyebaran Islam di Ternate, yakni Datuk Maulana Husein, disinyalir tiba di kawasan ini pada tahun 1965. Ia adalah seorang mubalig yang berasal dari Jawa yang memiliki kecakapan dalam bidang tilawah Alquran dan kaligrafi Arab. Di waktu senggah, terutama pada malam hari, ia membaca Alquran dengan suara merdu serta menciptakan seni kaligrafi di atas potongan-potongan papan. Keahlian tersebut menarik penduduk lokal Ternate. Banyak di antara mereka yang datang untuk mendengarkan lantunan ayat suci Alquran dan jumlahnya terus bertambah dari waktu ke waktu, hingga mereka meminta Datuk Maulana Husein untuk mengajarkan Alquran. Dalam penjelasannya, Husein menegaskan bahwa Alquran adalah kalam ilahi (verbum dei) yang hanya boleh diajarkan kepada mereka yang telah menganut agama Islam. Penduduk Ternate tidak keberatan dengan persyaratan tersebut dan berbondong-bondong memeluk Islam. Seiring

${ }^{6}$ M. Adnan Amal, Kepulauan Rempah-Rempah Perjalanan Sejarah Maluku Utara 1250-1950 (Jakarta: Kepustakaan Populer Gramedia, 2010), 206.

7 Hasan Atjo, Ternate Sejarah, Kebudayaan dan Pembangunan Perdamaian Maluku Utara (Yogyakarta: Ombak, 2009), 48. 
pertumbuhan jumlah penduduk Muslim di Ternate, termasuk juga yang berasal dari Tidore, Bacan, dan Jailolo, Husein membuka pengajian untuk mengajarkan Islam dan Alquran. Pendekatan dari level terbawah yang dilakukan Husein meningkat hingga ke lingkungan istana Kerajaan Ternate. Husein diminta membaca Alquran dan menjelaskan maksudnya di depan Kolano, para Bobato, dan keluarga istana, hingga akhirnya kalangan Istana Kerajaan Ternate memeluk agama Islam. ${ }^{8}$

\section{Peran Raja-raja dalam Islamisasi di Ternate}

1. Zainal Abidin (1486-1500)

Dalam banyak hal, Zainal Abidin memiliki sifat, watak dan kepribadian yang tidak jauh berbeda dengan ayahnya. Akan tetapi, dalam bidang keagamaan, Zainal Abidin memiliki peran yang melebihi ayahnya. Salah satu prestasi terbesarnya di bidang ini adalah perubahan struktur pemerintahan yang ia lakukan setelah kerajaan Ternate menerima Islam sebagai agama resmi.

Zainal Abidin memperoleh didikan formal dari Datuk Maulana Husein. Setelah itu, ia belajar di Gresik yang di bawah asuhan Sunan Giri (1495). Sejak hari-hari pertama bertakhta, Zainal Abidin menetapkan sejumlah kebijakan yang berdmpak pada perubahanperubahan struktural serta menetapkan sejumlah konvensi baru yang mendasar bagi kerajaan Ternate. Perubahan struktural, institusional, bahkan yudisial yang ia tetapkan, antara lain:

a. Perubahan gelar raja, dari Kolano yang digunakan raja-raja sebelumnya diganti dengan gelar Sultan yang menampilkan nilai islami.

b. Peresmian Islam sebagai agama kerajaan dan peralihan ke dalam bentuk kesultanan.

${ }^{8}$ Boedhihartono dkk., Sejarah Kebuadayaan Islam (Jakarta: Raja Grafindo Persada 2009), 191. 
c. Pembentukan lembaga baru dalam struktur pemerintahan dengan diangkatnya Lembaga Jolebe atau Bobato berjubah putih dan ditugaskan untuk membantu sultan dalam urusan-urusan keagamaan Islam serta mendampingi Bobato berjubah hitam yang telah bertugas membantu sultan dalam urusan pemerintahan.

d. Penetapan sultan sebagai pembina agama Islam atau Amir aldin yang membawahi Jolebe berjubah putih. Jolebe terdiri dari seorang Kalem (Kadi), 4 orang Imam, 8 orang Khatib dan 16 orang Moding, yang membantu 'Ämir al-Din menjalankan fungsi-fungsi keagamaan dan syariat Islam.

Perubahan struktur dan kelembagaan Kesultanan Ternate yang dilakukan oleh Sultan Zainal Abidin di atas memberikan pengaruh signifikan terhadap kerajaan-kerajaan lainnya di Kepulauan Maluku. Kerajaan-kerajaan seperti Tidore dan Bacan akhirnya menerapkan struktur dan lembaga kerajaan berdasarkan struktur dan kelembagaan baru di Kerajaan Ternate. ${ }^{9}$

2. Bayanullah (1500-1522)

Bayanullah menggantikan Zainal Abidin sebagai Sultan Ternate. Ia melanjutkan peran sultan sebagai 'Ämir al-Din di Ternate serta mendukung penyebaran Islam ke berbagai wilayah di sekitar Ternate. Ada dua ketetapan Bayanullah yang layak dicatat, yakni:

a. Kesultanan Ternate menetapkan pemberlakukan pernikahan dengan tata cara Islam bagi seluruh masyarakat di bawah kesultanan yang beragama Islam. Sultan Bayanullah juga melarang praktik pergundikan yang marak pada saat itu, khususnya di kalangan para Bobato.

b. Seluruh kawula kesultanan, tanpa pengecualian, baik Muslim maupun yang bukan, diharuskan berpakaian islami sesuai standar kerajaan. Sultan Bayanulah melarang laki-laki memakai

${ }^{9}$ M. Adnan Amal, Kepulauan Rempah-Rempah, 39. 
celana cawat (cikado) dan perempuan diharuskan memakai pakaian yang menutup aurat.

Untuk kedua keputusan di atas, Sultan Bayanullah memperoleh pujian dari pendatang Barat. Ia dipandang sebagai pelopor civilisasi rakyat Maluku. Sultan Bayanullah mempertegas Ternate sebagai kerajaan Islam. Berbagai peraturan yang bernafas Islam dibentuknya. Demikian pula, berbagai konvensi yang mengaitkan aktivitas kesultanan dengan penyebaran Islam diciptakannya. Seperti kebijakan yang diambil oleh Zainal Abidin, prinsip-prinsip dan konvensi-konvensi yang diletakkan Bayanullah diikuti oleh para sultan penggantinya dan berlaku sebagai sebuah tradisi kelembagaan yang juga menular kepada kerajaan-kerajaan di sekitar Ternate. ${ }^{10}$

Kerajaan Ternate didirikan di atas fondasi adat dan tradisi yang kukuh. Perbedaan-perbedaan yang muncul di sana-sini relatif tidak terkait dengan fondasi tersebut dan bukan merupakan faktor yang siginifikan. Bentuk-bentuk masyarakat yang pluralistik tidak menjadi handikap dalam komunikasi dan interaksi cultural pada masa-masa awal kerajaan-kerajaan tersebut, meskipun mesti diakui bahwa kondisi geografis sebagai kawasan dengan jumlah lebih dari tiga ratus pulau membawa kesulitan-kesulitan tersendiri. Namun, faktor-faktor penyatu di antara perbedaan tampak lebih dominan dalam konteks ini. Ada dua faktor utama yang inheren, sehingga menjaga persatuan penduduk di wilayah Kerajaan Ternate, yakni persamaan kultur dan faktor agama Islam. Naidah mengemukakan, dalam bahasa setempat, kedua faktor tersebut dikenal dengan sebutan, "Maluku kie raha ma asal rimoi bato, ma kabasaran se ma istiadat rimoi bato,"

${ }^{10}$ Ibid., 41. 
(Empat gunung Maluku sesungguhnya mempunyai satu asal-usul, punya kemegahan, dan kultur yang sama). ${ }^{11}$

\section{Dakwah Kultural sebagai Komunikasi Simbolik}

Dakwah kultural adalah aktivitas dakwah yang menekankan pendekatan Islam kultural. Yang dimaksud dengan Islam kultural adalah salah satu pendekatan yang berusaha meninjau kembali kaitan doktrin yang formal antara Islam dan politk atau Islam dan negara. Dakwah kultural hadir untuk mengukuhkan kearifan-kearifan lokal yang ada pada suatu pola budaya tertentu dengan cara memisahkannya dari unsur-unsur yang bertentangan dengan nilainilai. Dakwah kultural tidak menganggap kekuatan politik sebagai satu-satunya alat perjuangan dakwah. Pendekatan dakwah kultural menjelaskan bahwa dakwah sejatinya adalah membawa masyarakat agar mengenal kebaikan universal, yaitu kebaikan yang diakui oleh semua manusia tanpa mengenal batas ruang dan waktu.

Dakwah kultural merupakan upaya menanamkan nilai-nilai Islam dalam seluruh dimensi kehidupan dengan memperhatikan potensi dan kecenderungan manusia sebagai makhluk budaya secara luas dalam rangka mewujudkan masyarakat Islam yang sebenarbenarnya. Tujuan dari dakwah kultural adalah mencoba memahami potensi dan kecenderungan manusia sebagai makhluk budaya yang memahami ide-ide, adat istiadat, kebiasaan, nilai-nilai, norma, sistem aktivitas, simbol dan hal-hal fisik yang memilki makna tertentu dan hidup subur dalam kehidupan masyarakat. ${ }^{12}$

Menurut Sakareeya Bungo, seiring dengan semakin menurunnya peran Islam politik pada masa modern, yang ditandai

${ }^{11}$ Fakriati, Sejarah Sosial Kesultanan Ternate (Jakarta: Puslitbang Lektur Keagamaan Kementrian Agama RI, 2010), 174.

12 A M Hijran Mahjura, "Bentuk Dakwah Kultural." Diakses 14 Agustus 2017. http://amhiju05.blogspot.co.id/2016/04/bentuk-dakwahkultural-a.html. 
dengan terhapusnya sistem kekhalifahan di Turki dan dominasi Barat atas wilayah-wilayah penduduk mayoritas Islam, istilah dakwah menemukan kembali pengertian keagamaannya secara kultural. Dakwah memasukan aktifitas penyiaran (tablig), pendidikan dan pengembangan masyarakat sesuai dengan nilai-nilai Islam, baik untuk mad'ū muslim maupun non muslim. Untuk muslim, dakwahberfungsi sebagai proses peningkatan kualitas penerapan ajaran agama Islam. Sedangkan untuk non muslim fungsi dakwah minimal adalah memperkenalkan dan mengajak mereka agar memeluku agama Islam secara sukarela. ${ }^{13}$

Bagi Siti Hasanah, dakwah kultural sangat erat kaitannya dengan proses pemahaman Islam secara komprehensif yang melakukan internalisasi nilai-nilai Islam dalam aktivitas kehidupannya. Ajaran akidah, syariah dan akhlak dari dai terhadap mad'ù dapat diterapkan secara utuh, bukan setengah-setengah yang menyebabkan pada pola kehidupan yang memisahkan antara ajaran agama dengan urusan duniawi. ${ }^{14}$

\section{E. Nilai-Nilai Dakwah Kultural di Ternate}

Ternate merupakan wilayah dengan keragaman etnis dan budaya memiliki pengetahuan-pengetahuan lokal yang ada sejak dahulu. Representasi dari nilai kearifan lokal ini terdapat dalam corak ragam tradisi kelisanan masyarakat Ternate yang mewadahi pola pikir, sistem pengetahuan pranata sosial, serta falsafah hidup yang dijadikan sebagai pedoman hidup masyarakat Ternate. Segala artefak

13 Sakereeya Bungo, "Pendekatan Dakwah Kultural Dalam Masyarakat Plural," Jurnal Dakwah Tablig 15, no.2, (Desember 2014), 209219.

14 Siti Hasanah, "Inovasi Materi Dakwah Dari Ibadah ke Muamalah Bagi Ormas Islam untuk Merealisasikan Masyarakat Inklusif di Kota Semarang," Jurnal Dakwah Media Dakwah dan Komunikasi Islam 15, no. 2, (Desember 2014), 313-333. 
kebudayaan yang terepresentasi melalui aspek religi, sosialkemasyarakatan, sistem kepercayaan maupun dalam bidang seni dan kesusasteraan setempat.

Sebagian besar masyarakat Ternate masih menghargai dan melaksanakan tradisi peninggalan nenek moyang mereka. Beberapa di antara tradisi itu bahkan dimasukkan ke dalam kalender kegiatan tahunan. Ritual Kolilie Kie, misalnya, yaitu tradisi Keliling Gunung, yang merupakan sebuah ritual adat mengelilingi Gunung Gamalama sekaligus pulau Ternate yang dilakukan oleh sultan bersama permaisuri, pasukannya (kapita), dan rakyatnya (bala kusu sekano kano). Tradisi Kolilie Kie sarat dengan nuansa ajaran keislaman. Tradisi ini, selain dimaknai untuk mencegah bencana dan konflik, juga dimaksudkan untuk melepaskan nazar sebagai wujud ungkapan rasa syukur kepada Sang Pencipta. ${ }^{15}$

Hal ini dapat dibuktikan dengan beberapa fatwa yang memiliki nilai agamais dan filosifis, seperti dalam ungkapan bahasa Ternate berikut:

Toma Ua Hang Moju

Toma Limau Gapi Matubu

Gudu Moju si To Nonaku ri Jou si To Suba

Gudu Moju si To Suba Ri Jou Si To Nonako

Jou se Ngofa Ngare

(Dia ada jauh sebelumnya

Berada di Puncak Gunung Api

Dari kejauhan sudah kukenal sehingga ku sembah

Dari kejauhan ku sembah

karena pernah ku kenal sebelumnya.

Engkau dan Aku) ${ }^{16}$

15 Muhammad Irfan Syuhudi, "Pergerakan Islam di Universitas Khairun Ternate," Analisa: Journal of Social Science and Religion 22, no. 2, (Desember 2015), 255-268.

${ }^{16}$ Fakriati, Sejarah Sosial, 161. 
Dasar inilah yang membentuk karakter budaya masyarakat Ternate yang agamais, filosofis, mistis. dan estatis. Sikap yang ditunjukan dalam keberagaman yang cenderung mistis, akan tetapi memperlihatkan sikap yang inklusif dalam persoalan sosial. Simbolsimbol budaya Ternate dalam variasi makna, baik yang berkaitan dengan refleksi budaya dasar manusia yakni pangan, pakai dan papan dalam kehidupan sehari-hari, sarat dengan nilai Islam. ${ }^{17}$

Terdapat enam sistem hukum pemerintahan Ternate yang perlu dielaborasi lebih dulu dalam mendiskusikan kebudayaan masyarakat setempat, antara lain:

1. Adat Se Atorang. Hukum dasar atau undang-undang yang dipenuhi dan disusun menurut kebiasaan yang dapat diterima semua warga. Misalnya, kepada golongan Islam berlaku hukum Islam dan kepada yang bukan Islam hukum tersendiri sesuai dengan prinsip hidup atau kepercayaan yang dianutnya.

2. Istiadat se Kabasarang. Lembaga adat dan kekuasaannya menurut ketentuan yang telah ditetapkan. Dimaksud adalah kekuasaan dan hak-hak raja.

3. Galib Se Likudi. Kebiasaan lama yang menjadi pegangan suku, diatur menurut sendi kekuatan yang berkaitan denganhak asal usul dan hak-hak asasi.

4. Ngele Se Duhu. Bentuk budaya masing-masing suku di Ternate dapat digunakan secara bersama sesuai dengan keinginan.

5. Sere se Doniru. Tata kehidupan seni budaya dan kebiasaan yang timbul dalam pergaulan masyarakat yang diterima secara bersama.

6. Cing se Cingare. Pasangan pria dan wanita merupakan satu kesatuan yang utuh dengan hak dan kewajiban masing-masing perlu dibina dan dijaga kelestariannya. ${ }^{18}$

\footnotetext{
17 Ibid.

${ }^{18}$ Ibid., 162.
} 
Masyarakat Ternate secara sosio-kultural dikenal teguh dalam menjaga dan memelihara tradisi budaya lokal mereka. Sebagian masyarakat meyakini, tradisi dan ritual tersebut tetap harus dilaksanakan sebagai bentuk dari kearifan lokal. Mereka juga meyakini bahwa tradisi dan ritual yang dilaksanakan ikut mempengaruhi kehidupan mereka di masa mendatang.

Sikap umat Islam Ternate yang sangat akomodatif dengan budaya pra Islam disebabkan karena nilai-nilai lokal dianggap tidak bertentangan dengan ajaran Islam. Masyarakat Islam Ternate hidup dalam kultur Islam yang kooperatif, mengingat masyarakat Islam Ternate mengikuti paham teologi Ahlus Sunnah wal Jamaah, yaitu paham teologi yang dianut oleh mayoritas umat Islam Indonesia.

Tidak seperti kondisi sosial dan kebudayaan di wilayah lainnya di Indonesia, kehidupan sosial dan budaya masyarakat Ternate menampilkan corak yang berbeda. Perbedaan tersebut, menurut Yusuf Abdulrahman mengalami time character dari zaman ke zaman. Paling tidak terjadi akulturasi atau persilangan budaya yang menyebabkan terjadinya adopsi kebudayaan. Sentralisasi budaya tersebut dapat dibuktikan melalui sebaran seni dan budaya hingga sekarang ini yang lebih banyak dipengaruhi atau menggunakan bahasa Ternate. Sebaran seni dan budaya di Ternate juga tidak dapat dilepaskan dari kebudayaan luar, khususnya budaya pedagang (Arab dan China) dan penjajah (Spanyol, Portugis dan Belanda serta Jepang). ${ }^{19}$

Sehubungan dengan hal di atas, terdapat beberapa seni budaya dan tari yang merepresentasikan bentuk dakwah kultural pada masyarakat Ternate, yaitu:

\section{Tari Gala (Ronggeng Gala)}

19 Yusuf Abdulrahman, Tradisi Lisan Kerajaan Ternate dan Perdagangan Cengkeh, dalam Ternate sebagai Bandar di Jalur Sutra (Jakarta: Depdikbud, 1997), 197. 
Tari gala merupakan jenis kesenian khas Ternate yang masih banyak digemari oleh masyarakatnya. Tarian Gala lazimnya digelar pada pelaksanaan acara sunatan, pesta pernikahan, pesta rakyat, dan penjemputan tamu. Tarian Gala atau dalam bahasa lokal disebut Ronggeng Gala dipentaskan dengan iringan musik khas Ternate, alat musik yang terdiri dari sebuah seruling, tifa dan sebuah gong.

Dalam menari gala, perempuan selalu berada di tengah. Penempatan ini merupakan simbol yang menandakan posisi perempuan yang lemah, sehingga harus dilindungi oleh laki-laki. Perempuan juga memiliki sebuah selendang dan sebuah saputangan (lenso) yang dalam berdendang berjalan sejajar dengan pasangannya. Keduanya memegang ujung saputangan untuk menghindari persentuan kulit. $^{20}$

2. Tarian Dansa (Dadansa)

Dadansa adalah sendratari yang berhubungan khusus dengan acara keluarga para Sultan yang diperkenalkan sekitar abad ke 17. Tari ini bukan tarian asli Ternate. Beberapa sumber menyebutkan bahwa dadansa berasal dari Portugis. Penari dadansa terdiri atas 11 orang pria yang berbaris layaknya para prajurit Portugis, berpakian lengkap.

Hal ini membuktikan bahwa tradisi Ternate, selain memiliki akulturasi, enkulurasi dan adopsi juga terjadi. Dadansa diciptakan pada masa Sultan Bayanullah dan dijadikan kesenian istana. Oleh karena itu Dadansa hanya dipertunjukan setahun sekali di keraton dalam rangka memperingati hari jadi Kesultanan Ternate dan hanya boleh dipentaskan oleh kelompok Soa Ngare (Petugas Istana).

\section{Tamsil Dodoto}

Seperti dalam kesustraan Indonesia, tamsil dalam sastra lisan Ternate berisi nasehat dan petunjuk mengandung unsur keagamaan, sebagai peringatan kepada pemeluknya agar benar-benar

\footnotetext{
${ }^{20}$ Fakriati, Sejarah Sosial, 164.
} 
mempelajari ilmu agama dan mengamalkannya selama masih hidup. Penyajian tamsil dilakukan oleh pemuka agama pada acara berkabung hari kematian di rumah tempat acara berkabung itu dilakukan. Tujuannya supaya pendengar yang hadir dalam acara berkabung turut mengenang bahwa mereka pun akan wafat. Ini mempunyai arti bahwa kematian itu datang menjenguk seseorang tanpa ada pemberitahuan terlebih dahulu. Masyarakat Ternate percaya bahwa, selagi masih ada kesempatan hidup, manusia perlu menelusuri dan menuntun tuntutan yang diwajibkan agama. ${ }^{21}$

Selain ketiga tarian di atas, masyarakat Ternate juga mempunyai tradisi kepercayaan pada hal-hal metafisika yang membaur dengan unsur Islam dan anismisme, di antaranya:

1. Tarian Jin (Salai Jin), yaitu sejenis tarian pasangan muda-mudi dengan mantra-mantra khusus. Seorang wanita dipilih sebagai pemimpin dalam tarian tersebut dengan iringan sesajen yang dilengkapi dengan bunyi bunyian tifa, gong, serta ucapan mantra yang meyakinkan.

2. Ela-Ela adalah tradisi atau kearifan lokal sebagai penyambutan malam lailatulkadar. Malam lailatulkadar dianggap sakral, sehingga harus dihormati dan ditaati. Sebagai bentuk penghormatan pada malam lailatulkadar, masyarakat Ternate menyalakan lampu setelah waktu magrib hingga pagi tiba. Lampu-lampu ini terbuat dari damar, kelapa kering, hingga obor yang diletakan di depan rumah masing-masing warga. Selain di depan rumah, lampu-lampu juga diletakan di kuburan sebagai refleksi kepada saudara, anak, atau orang tua yang telah meninggal dunia. Di lingkungan kerajaan, Sultan saat hendak melaksanakan salat tarawih, sesuai tradisi, harus ditandu. Sultan dipikul secara bergantian oleh rakyatnya

${ }^{21}$ Ibid., 175. 
dengan membawa obor atau lilin sebagai tanda penerangan jalan yang disertai tabu gong. ${ }^{22}$

\section{F. Kesimpulan}

Aktualisasi dakwah kultural Islam dalam lintasan sejarah masyarakat dan Kesultanan Ternate telah menjadikan nilai-nilai Islam tidak dapat dipisahkan dari aspek lokalitas, mulai dari budaya Arab, Persia, Turki, India sampai Melayu. Masing-masing bentuk kultural, sebagaimana telah dipaparkan di atas, mencerminkan nilai-nilai sebagai benang merah yang mengikat secara kokoh satu sama lain. Kreatifitas kebudayaan seperti sistem hukum kesultanan, tarian, dan ritual keislaman masyarakat Muslim di Ternate merupakan penanda relasi antara Islam sebagai agama dengan adat dan budaya lokal yang dapat ditindaklanjuti dalam kajian antropologi agama.

\section{Daftar Pustaka}

Abdulrahman, Yusuf. Tradisi Lisan Kerajaan Ternate dan Perdagangan Cengkeh, dalam Ternate sebagai Bandar di Jalur Sutra. Jakarta: Depdikbud, 1997.

Amal, M. Adnan. Kepulauan Rempah-Rempah Perjalanan Sejarah Maluku Utara 1250-1950. Jakarta: Kepustakaan Populer Gramedia, 2010.

Ambary, Hasan Muarif. Menemukan Peradaban Jejak Arkeologis dan Historis Islam Indonesia. Jakarta: Logos Wacana Ilmu, 1998.

Atjo, Hasan. Ternate Sejarah, Kebudayaan dan Pembangunan Perdamaian Maluku Utara. Yogyakarta: Ombak, 2009.

Azra, Azyumardi. Jaringan Ulama. Bandung: Mizan, 1995.

Boedhihartono dkk. Sejarah Kebuadayaan Islam. Jakarta: Raja Grafindo Persada 2009.

${ }^{22}$ Ibid., 218. 
Bungo, Sakereeya. "Pendekatan Dakwah Kultural Dalam Masyarakat Plural." Jurnal Dakwah Tablig 15, no.2, (Desember 2014): 209-219.

Fakriati, Sejarah Sosial Kesultanan Ternate. Jakarta: Puslitbang Lektur Keagamaan Kementrian Agama RI, 2010.

Hasanah, Siti. "Inovasi Materi Dakwah Dari Ibadah ke Muamalah Bagi Ormas Islam untuk Merealisasikan Masyarakat Inklusif di Kota Semarang." Jurnal Dakwah Media Dakwah dan Komunikasi Islam 15, no. 2, (Desember 2014): 313-333.

Ilaihi, Wahyu dan Harjani Hefni. Pengantar Sejarah Gerakan Dakwah. Jakarta: Kencana, 2007.

Mahjura, A M Hijran. "Bentuk Dakwah Kultural." Diakses 14 Agustus 2017. http://amhiju05.blogspot.co.id/2016/04/bentuk-dakwahkultural-a.html.

Syamsuriah. "Tradisi Budaya dan Tradisi Agama dalam Kehidupan Sosial." Al-Mishbah: Jurnal Ilmu Dakwah dan Komunikasi 9, no. 1 (Juni 2013): 63-76.

Syuhudi, Muhammad Irfan. "Pergerakan Islam di Universitas Khairun Ternate." Analisa: Journal of Social Science and Religion 22, no. 2, (Desember 2015): 255-268. 